\title{
FATIGUE CRACK INITIATION AND DAMAGE CHARACTERIZATION IN BRAZILIAN TEST SPECIMENS FOR ADHESIVE JOINTS
}

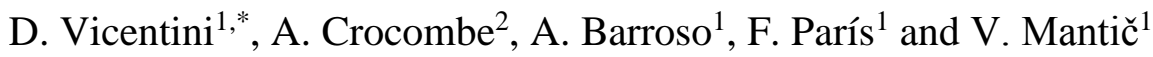 \\ ${ }^{1}$ School of Engineering, University of Seville, Camino de los Descubrimientos s/n, 41092, Sevilla, \\ Spain \\ ${ }^{2}$ Mechanical, Medical and Aerospace Engineering, University of Surrey, Guildford GU2 7XH, UK
}

\begin{abstract}
The present study is focused on the fatigue failure initiation at bimaterial corners by means of a configuration based on the Brazilian disk specimens. These specimens were previously used for the generalized fracture toughness determination and prediction of failure in adhesive joints, carried out under static compressive loading. Under static loading, local yielding effects might affect the asymptotic two-dimensional linear elastic stress representation under consideration. Fatigue loading avoids this fact due to the lower load levels used. The tests were performed using load control; video microscopy and still cameras were used for monitoring initiation and crack growth. The fatigue tests were halted periodically and images of the corner were taken where fatigue damage was anticipated. Damage initiation and subsequent crack growth were observed in some specimens, especially in those which presented brittle failure under static and fatigue tests. These analyses allowed the characterization of damage initiation for a typical bimaterial corner that can be found in composite to aluminium adhesive lap joints.
\end{abstract}

Keywords: adhesive joints, failure, crack initiation, composites, fatigue.

\section{Introduction}

Many proposals to determine the stress state in adhesive joints, for failure prediction, have been presented over the years. Several analytical works studying adhesive lap joints can be found in the literature. The classical works of Volkersen [1], de Bruyne [2] and Goland and Reissner [3] that used elasticity and a strength of materials approach (based on thin plates or beam theory, for

\footnotetext{
* Corresponding author. Tel.: +34 954487 300; Fax.: +34 954461637.

Email address: danianevicentini@gmail.com
} 
example) are generally recognized as constituting the pioneering work in this field. Later on, Wah [4] introduced composites in the analysis of lap joints and Hart-Smith [5, 6], in addition, included other improvements for designing adhesive joints, such as the study of thermal stresses, joint efficiency, the effect of the stacking sequence, unbalanced joints, etc. More recently, the work of Tsai and co-workers $[7,8]$ in which the shear stresses are assumed to vary linearly through the thickness direction are highlighted. Also Bigwood and Crocombe $[9,10]$ proposed a generic analysis from plate bending theory for different types of configurations of joints under complex loading. A good review of the literature concerning the stress analysis of adhesive joints can be found in da Silva et al. [11]. Another interesting work by da Silva et al. [12] compares some of the analytical models against experiments, finding that models were too conservative. All these works, however, aimed, in part, to predict the joint strength based on nominal stresses under static loading.

Other proposals using a fracture mechanics approach and motivated by the existence of stress singularities at the corners in the joints have been presented in $[13,14,15,16]$, among others. More recently, a criterion based on the local singular stress state of the bimaterial corner encompassed by the joint, where the failure is expected to initiate, was proposed [17] and verified experimentally [18]. A new test for the determination of the critical values of the Generalized Stress Intensity Factors (GSIFs) appearing in this corner configuration was proposed, based on the original Brazilian Test (BT) specimen [19]. This geometry was chosen because it allows the entire range of mode mixities to be covered $[17,18]$. The experiments carried out [18] strongly suggest that the proposed criterion could be applied in real adhesive joints [20] with the same local corner configuration at the end of the overlap zone. Following this line, the present work studied the failure generated in the corner but under fatigue loads. The lower level of load that is applied in fatigue tests generally produces a stress state free of plasticity effects. Also, this work aimed to characterize the development of fatigue cracks (initiation and propagation) for the present type of geometry. 
Although thermal stresses have been reported to have a significant influence on the behaviour of adhesive joints between dissimilar materials [21], the stresses being actually more severe in the Double Lap Joint (DLJ) than in the BT specimen, thermal analysis has not been included in the present work, following previous experience in similar corner geometries [22].

\section{Failure criterion based on fracture toughness for adhesive joints}

By analogy to the Linear Elastic Fracture Mechanics (LEFM) for homogeneous and brittle (or quasi-brittle) materials, the present work seeks to predict the failure onset by using critical values of the GSIFs (or generalized fracture toughnesses), under which the failure of the corner is expected to initiate $[17,18]$. According to this hypothesis and assuming generalized plane strain, the singular stress state around the tip of a multimaterial corner can be approximated by a truncated sum of $n$ terms (see [17] for pertinent references):

$\sigma_{i j}(r, \theta) \cong \sum_{k=1}^{n} \frac{K_{k}}{r^{1-\lambda_{k}}} f_{i j}^{k}(\theta) \quad$ for $i, j=r, \theta$

where the characteristic exponents $\lambda_{\mathrm{k}}$ have a positive real part, $\operatorname{Re} \lambda_{\mathrm{k}}>0, \mathrm{f}_{\mathrm{ij}}{ }^{\mathrm{k}}$ are the characteristic angular shape functions, and $(r, \theta)$ are the polar coordinates centred at the corner tip (Fig. 1 a). When $\operatorname{Re}\left(1-\lambda_{\mathrm{k}}\right)$ is between 0 and $1,\left(1-\lambda_{\mathrm{k}}\right)$ is called the stress singularity order. When $\mathrm{r}$ tends to zero, the corresponding terms of Eq. (1) go to infinity. The GSIF $\left(\mathrm{K}_{\mathrm{k}}\right)$ can be determined numerically, e.g. by using a least squares technique, while the angular shape functions and characteristic exponents can be determined semi-analytically (see [17, 23 or 24] for more details). In some corner configurations, stresses $\sigma_{\mathrm{ij}}(\mathrm{r}, \theta)$ for $\mathrm{r} \rightarrow 0$ are well approximated by the most singular term in the asymptotic expansion (1), defining the singular stress state by only one $\mathrm{K}_{\mathrm{k}}$. Under increasing static load in a configuration controlled by only one $\mathrm{K}_{\mathrm{k}}$, once the corner reached the maximum admissible level of stress, the generalized fracture toughness $\mathrm{K}_{\mathrm{kC}}$ can be determined. Following this reasoning, when singular stresses are approximated by two or three terms of the series expansion (Eq.1), the critical combinations of GSIFs would define a failure envelope curve or surface, enclosing the safety region. This failure envelope should be determined by testing 
several load configurations. These tests can define some intermediate points to obtain the hypothetical failure curve or surface, as schematically shown in Fig. 1b (see Hattori [13] for single lap joints and Wang and Suo [25] and Banks-Sills et al. [14] for interfacial cracks).

\section{Configuration of the specimens}

The problem under consideration is defined by a particular corner of a DLJ, in which the stress state is the most severe and thus the failure is expected to initiate. This corner is formed by a Carbon Fibre Reinforced Polymer (CFRP) laminated adherend and adhesive layer and spew fillet, as can be seen in Fig. $1 \mathrm{c}$.

In the original problem, the DLJ (whose adherends were aluminium and CFRP) was bonded using a structural adhesive (Fig. $1 \mathrm{c}$ ). The same adhesive and CFRP were used in both geometries, DLJ and BT (Fig. $1 \mathrm{c}$ and $\mathrm{d}$ ). For the bimaterial corner in the BT, $\mathrm{R}$ was the radius and the thickness of the specimen (Fig. $1 \mathrm{~d}$ ). The following material properties (given by the manufacturer's data sheet) were considered: $\mathrm{E}=68670 \mathrm{MPa}$ (Young's Modulus), $v=0.33$ (Poisson's ratio) for aluminium 2024-T3; $\mathrm{E}_{\mathrm{x}}=141300 \mathrm{MPa}, \mathrm{E}_{\mathrm{y}}=\mathrm{E}_{\mathrm{z}}=9580 \mathrm{MPa}, v_{\mathrm{xy}}=v_{\mathrm{xz}}=0.3, v_{\mathrm{yz}}=0.32, \mathrm{G}_{\mathrm{yz}}=3500 \mathrm{MPa}, \mathrm{G}_{\mathrm{xy}}=$ $\mathrm{G}_{\mathrm{xz}}=5000 \mathrm{MPa}$ for CFRP AS4/8552 unidirectional fibre laminate $[0]_{12}(\mathrm{x}$ being the fibre direction, Fig. 1 d) and $\mathrm{E}=3000 \mathrm{MPa}, v=0.35$ for the adhesive $\mathrm{FM}^{\circledR} 73$ OST (toughened epoxy film, from Cytec).

For this particular corner, the three first terms in Eq. (1) were considered ( $n=3)$, so the asymptotic stress state in the neighbourhood of the corner tip can be expressed by the following series expansion $[24,26]$ :

$\sigma_{\mathrm{ij}}(\mathrm{r}, \theta) \cong \frac{\mathrm{K}_{1}}{\mathrm{r}^{1-\lambda_{1}}} \mathrm{f}_{\mathrm{ij}}^{1}(\theta)+\frac{\mathrm{K}_{2}}{\mathrm{r}^{1-\lambda_{2}}} \mathrm{f}_{\mathrm{ij}}^{2}(\theta)+\frac{\mathrm{K}_{3}}{\mathrm{r}^{1-\lambda_{3}}} \mathrm{f}_{\mathrm{ij}}^{3}(\theta) \quad\left(\right.$ for $\mathrm{r} \rightarrow 0^{+}$and $\left.\operatorname{Re} \lambda_{\mathrm{k}}>0\right)$

where $\lambda_{1}=0.763, \lambda_{2}=0.889$ and $\lambda_{3}=1.107$ (from [20]) are the stress singularity exponents (for example in LEFM for a crack problem in mixed mode I and II these exponents would be $\lambda_{1}=\lambda_{2}=$ $0.5) ; K_{1}, K_{2}$ and $K_{3}$ are the GSIFs which represent the weight of each term of the series expansion. The characteristic exponents $\left(\lambda_{\mathrm{k}}\right)$ and angular shape functions $\left(\mathrm{f}_{\mathrm{ij}}^{\mathrm{k}}\right)$ depend on the local geometry, 
material properties and boundary conditions at the corner tip and they were obtained using the semi-analytical procedure developed in [24], normalized according to Pageau et al. [27] and studied in [17]. When $r$ tends to zero, the two first terms (which are singular) are the most significant ones in this equation; thus in this work, for very small distances (r) from the corner tip, the third term in Eq. (2) can be neglected, without loss of generality. So the stress field can be expressed as:

$$
\sigma_{\mathrm{ij}}(\mathrm{r}, \theta) \cong \frac{\mathrm{K}_{1}}{\mathrm{r}^{0.236764}} \mathrm{f}_{\mathrm{ij}}^{1}(\theta)+\frac{\mathrm{K}_{2}}{\mathrm{r}^{0.110611}} \mathrm{f}_{\mathrm{ij}}^{2}(\theta) \quad\left(\text { for } \mathrm{r} \rightarrow 0^{+}\right)
$$

The stresses can be obtained numerically when, considering for example the bimaterial rounded corner, a uniform load $\mathrm{P}$ (see Fig. $1 \mathrm{~d}$ ) is diametrally applied along the thickness. Then $\mathrm{K}_{1}$ and $\mathrm{K}_{2}$ can be evaluated in order to isolate each term.

\subsection{The proposed failure envelope based on critical GSIF}

The BT (indirect tensile or splitting tensile test) represented in Fig. 1 d, also known as diametral compression test, is used for the assessment of the tensile strength of brittle or quasi-brittle materials, especially concrete and rocks. The test consists of a cylindrical specimen (with radius $\mathrm{R}$ and thickness t) diametrally loaded (P) under compression. It was first published by Carneiro in 1943, according to the reference [19]. As a curiosity, this test was proposed to check the strength of concrete cylinders which would have been required for moving the ancient São Pedro Church in Rio de Janeiro to another location within the city. The test was independently proposed by Akazawa (according to the reference [28]) some months later and has become a very popular test due to its versatility, usage and consistency (scatter less than 10\%) compared with other methods [29].

Varying the direction of the symmetrical load P according to different angles $(\alpha)$ for the particular bimaterial corner under study (Fig. 1 d), the distributions of the GSIFs $\left(\mathrm{K}_{1}\right.$ and $\mathrm{K}_{2}$ ) are presented in Fig. 2 [17]. 
From this graph, it can be deduced that the isolation of the mode related to $\mathrm{K}_{1}$ (where $\mathrm{K}_{2}$ vanishes) is achieved for $\alpha \approx 13^{\circ}$ or $\alpha \approx 115^{\circ}$, and the mode related to $K_{2}$ for $\alpha \approx 60^{\circ}$ or $\alpha \approx 143^{\circ}$ (where $K_{1}$ vanishes).

It is important to note that the GSIFs depend on the specimen geometry, material properties and boundary conditions. From the observation that the GSIFs are proportional to the load and inversely proportional to the specimen radius and thickness [18], the critical GSIF value $\mathrm{K}_{\mathrm{kC}}{ }^{\mathrm{spec}}$ (the value of GSIF at failure) can be correlated to the numerical GSIF value $\mathrm{K}_{\mathrm{k}}{ }^{\text {num }}$ by means of the following expression:

$$
K_{\mathrm{kC}}^{\mathrm{spec}} \cong \frac{\mathrm{P}^{\mathrm{spec}} \mathrm{R}^{\mathrm{num}} \mathrm{t}^{\mathrm{num}}}{\mathrm{P}^{\mathrm{num}} \mathrm{R}^{\mathrm{spec}} t^{\mathrm{spec}}} K_{\mathrm{k}}^{\mathrm{num}}
$$

where $\mathrm{K}_{\mathrm{kC}}{ }^{\mathrm{spec}}, \mathrm{P}^{\mathrm{spec}}, \mathrm{R}^{\mathrm{spec}}, \mathrm{t}^{\mathrm{spec}}$ are the parameters from the tested specimens: GSIF (critical, calculated from Eq. (4)), ultimate (compressive) load (given by the test, thus $\mathrm{P}^{\mathrm{spec}}=\mathrm{P}_{\mathrm{u}}$ ), radius and thickness of the specimen (both measured before testing). $K_{k}{ }^{\text {num }}, P^{\text {num }}, R^{\text {num }}, t^{\text {num }}$ are the analogous parameters from the numerical analysis, the values used in this work being $R^{\text {num }}=t^{\text {num }}=1 \mathrm{~mm}$ and $\mathrm{P}^{\text {num }}=100 \mathrm{~N}$. The parameters measured in experimental test, the estimated $\mathrm{P}_{\mathrm{u}}$ from previous static tests [18] and the critical GSIFs calculated from this estimation are presented in Table 1.

Defining a failure criterion in terms of strength, some size-scale effects will appear. Applying a dimensional analysis, the generalized stress intensity factor can be expressed as (see $[17,18,30]$ and references therein):

$$
\mathrm{K}_{\mathrm{k}}=\sigma_{\mathrm{nom}} \mathrm{R}^{1-\operatorname{Re}\left(\lambda_{\mathrm{k}}\right)} \mathrm{A}_{\mathrm{k}} \quad(\mathrm{k}=1,2)
$$

where $\sigma_{\text {nom }}$ is a nominal stress in the problem, $R$ is a characteristic distance (the radius in the present case) and $A_{k}$ is a shape factor taking into account the geometry and material properties of the problem.

A generalized fracture-toughness based failure criterion could be expressed, in the generic form, as:

$$
K=\kappa_{C}(\psi)
$$


where $K=\sqrt{\left(\frac{K_{1}}{K_{1 C}}\right)^{2}+\left(\frac{K_{2}}{K_{2 C}}\right)^{2}}$ is a normalized GSIF modulus (a dimensionless magnitude) and $\psi$ is a normalized fracture mode-mixity angle, $\tan \psi=\left(K_{2} / K_{2 C}\right) /\left(K_{1} / K_{1 C}\right)$. Unlike the traditional mode mixity definition in the case of a crack, $\tan \psi=\left(K_{2} / K_{1}\right)$, the inclusion of the fracture toughnesses is due to the different units of $\mathrm{K}_{1}$ and $\mathrm{K}_{2}$ in the present case. The parameterization $\left(\psi, \kappa_{C}(\psi)\right)$ defines a hypothetical failure envelope based on generalized fracture-toughness concepts [18]. It should be emphasized that using (5) and (6), an explicit expression for the sizescale effect on the specimen strength can be deduced.

\section{Fabrication of the BT specimens}

For the fatigue tests, BT disk specimens were manufactured by curing in an autoclave. Eight different angles $\alpha$ (for application of P, according to Fig. 2) were tested, using 3 specimens for each angle. From previous experience [18, 31], the following detailed process was adopted because it seemed to be the most suitable, in order to obtain the best quality samples (absence of porosity).

First, a CFRP laminate of 120 plies previously manufactured was cut to adopt the shape of a square prism, which was partitioned into little square slices of dimensions $20 \times 20 \times 10 \mathrm{~mm}$, the thickness being $10 \mathrm{~mm}$ and the direction of fibres being parallel to one of the $20 \mathrm{~mm}$ length edges. The slices were then cleaned with acetone.

The adhesive was supplied as a tacky film which was left out of the freezer some hours before bonding. The adhesive film was cut and layered with intermediate vacuum compaction between every five laminas for 10-15 min until completely covering the CFRP square width (Fig. 3.a). The procedure was carried out inside a clean room. The entire set was placed on an aluminium plate covered with Teflon ${ }^{\circledR}$. Cork was used to separate and contain all specimens, accommodating and fixing them to the plate. Next, the cork was covered with a high temperature tape to avoid spilling of the adhesive during the curing process (Fig. 3.b).

The entire set was covered with Teflon ${ }^{\circledR}$, followed by an Airweave ${ }^{\circledR}$ breather fabric (from Airtech 
Europe Sarl, Luxembourg). Then a vacuum bag was prepared, and the specimens were cured inside the autoclave under $0.28 \mathrm{MPa}(2.8 \mathrm{bar}), 120^{\circ} \mathrm{C}(393 \mathrm{~K})$ and $105 \mathrm{~min}$ in total. After the curing process, every specimen was a square plate (see Fig. 3.c). In [18] a schematic figure of the whole manufacturing process is available.

Once the curing cycle was finished, every sample was carefully cut, using a water-cooled diamond for cutting the circular disk, around the marked circumference of the final geometry (Fig. $3 \mathrm{c}$ ). Then the specimens were abraded in order to smooth the cut surfaces, leaving them as round as possible. The final dimensions (in terms of $\mathrm{R}$ and $\mathrm{t}$ ) of the specimens are presented in Table 1 . Finally, the angle of the load application was marked and both "flats" on which the load was applied (Fig. 3.d) were cut. This allowed a uniform application of the compressive load during the test (by Saint-Venant principle the stress state at the corner tip is not affected by the local detail of the load application, as can be verified in [32], for example, among other studies).

\section{Experimental test}

In a previous work [18], BT disk specimens were tested under static load in a displacement controlled machine for different angles $\alpha$, in order to achieve the failure envelope according to the theory presented in [17] and summarized in previous sections. A failure envelope based on the critical combinations of a pair of GSIFs at the corner tip was presented and proposed as a criterion for joints having the corner shown in Fig. 1 d. The results were compared (in [18]) with real adhesively bonded DLJs loaded in tension (that were previously tested in [20]), presenting good agreement. In addition, if plasticity occurred it could affect the stress state of the corner. In this sense, fatigue tests could be useful to avoid possible yielding effects. Such tests have been carried out in the present work in order to further characterize the crack initiation and damage progression. Failure initiation in the current work was defined as the first of the following phenomena: initial observation of whitening or a crack.

The fatigue tests were halted every 5000 cycles to check the integrity of the specimen on both planar surfaces. The test was considered to be finished either when the failure length was 
approximately equal to, or greater than, $3 \mathrm{~mm}$, or when the specimen reached a total of $10^{5}$ cycles (equivalent to a couple of days of cycling). This failure length was chosen in order to optimize the visualization of one or more cracks, the time needed for testing and the safety of the machine.

\subsection{Mechanical testing and parameters}

The tests were carried out in a servo-hydraulic Instron 8511 machine, in sinusoidal load control at a frequency of $5 \mathrm{~Hz}$. The room temperature was $25 \pm 3^{\circ} \mathrm{C}$ during the testing. Additionally, the machine was provided with automatic amplitude control for better stability of the tests. No static test was undertaken for this series of specimens, so the ultimate compressive load $\left(\mathrm{P}_{\mathrm{u}}\right)$ was estimated from data presented in [18]. $\mathrm{P}_{\mathrm{u}}$ was estimated to be $13260 \mathrm{~N}$ on average (a small variation was observed between specimens due to small changes in geometry). Thus, a compressive load $\mathrm{P}_{\max }=6540 \mathrm{~N}$ was used (corresponding to nearly $50 \%$, of the estimated $\mathrm{P}_{\mathrm{u}}$, in most cases) in the first tests. However, this load did not allow the initiation of failure in the majority of the initial batch of test specimens. Thus, $\mathrm{P}_{\max }$ was changed to $8409 \mathrm{~N}$ (corresponding to around $60 \%$ of the estimated $\mathrm{P}_{\mathrm{u}}$. The minimum load was chosen as $10 \%$ of $\mathrm{P}_{\max }$, giving a fully compressive load cycle and a load ratio $\left(\mathrm{P}_{\min } / \mathrm{P}_{\max }\right)$ of 0.1 . Also, a fan was used to help maintain the specimens at room temperature and compensate for the slight heat generation due to the lights

required for the cameras. Two flat plates were used as platens to apply compression on the "flats" machined in the specimen. Initially for a better monitoring of temperature, a thermocouple was used with the first few samples. However, as was later verified that the temperature was quite constant, it was no longer necessary to check temperature during the tests.

\subsection{Damage monitoring}

Pictures from three different cameras were taken to capture the initiation and eventually the progression of failure. They had different magnifications and qualities of images and videos, and were positioned close to the corner tip, where failure was expected to initiate. At every programmed interruption of the machine test (every 5000 cycles), one or two pictures (or a video) were taken of one (or both, when possible) surfaces of the specimen. The pictures taken were viewed successively at the end of the test, providing visualisation of the initiation and progression 
of the failure. Figure 4 shows an example of sequential pictures for one specimen. Figure 4 a) shows a picture of the specimen before testing, without any cracks. Figure 4 b) shows a picture taken after 70000 cycles. In this picture, a crack/whitening can be seen at the CFRP-adhesive interfaces around both sides of the corner. Figure 4 c) was taken at the end of test, in which the crack grew from one CFRP-adhesive interface through the adhesive.

A small piece of graph paper (with a grid of $1 \mathrm{~mm} \times 1 \mathrm{~mm}$ ) was attached to the CFRP for scale measurement in each specimen, (Fig. 4). The resolution of the camera was 50 pixels/mm (1270 dpi); the accuracy of the crack length measurement being $0.02 \mathrm{~mm}$ per pixel, which was precise enough for the prescribed $1 \mathrm{~mm}$ and $3 \mathrm{~mm}$ measurements. Extracting the information from the images, $\mathrm{N}_{0}$ was defined as the number of cycles at which the first change was observed in the corner, $\mathrm{N}_{1 \mathrm{~mm}}$ as the number of cycles necessary for the observed damage to reach at least $1 \mathrm{~mm}$ in length, and $\mathrm{N}_{3 \mathrm{~mm}}$ as the number of cycles necessary for the observed damage to reach at least 3 $\mathrm{mm}$ in length.

The analysis of pictures was based only on visual measurement of the scaled images, i.e., no image analysis software was used. For irregular damage/whitening/cracks the approach outlined in Fig. 5 was taken as a guide, and when the failure was slightly different on both sides, the most extreme situation was considered for the analyses.

\section{Results and discussion}

The fatigue tests were interrupted every 5000 cycles, except when an instantaneous and/or sufficiently large crack occurred in which case the test was finished. At every interruption of the test, the number of cycles was recorded. For regular tests at every 5000 cycles, it was assumed that any damage event occurred mid-way through the prior band (i.e., in the intermediate number of cycles corresponding to the centre of the actual range) of cycles.

\subsection{Failure evolution}

Figure 6 shows the failure evolution for every group of specimens (called, for internal control, PC followed by the number of the specimen). The angles considered for every set of specimen are 
shown in Table 1. In Fig. 6, the load level applied was indicated in each graph. The group of specimens with $\alpha=60^{\circ}$ (PC7 to PC9) did not present any visible failure, so this configuration was not represented in Fig. 6.

In the cases where the failure started quickly, some specimens were tested under two load levels (PC7, PC8, PC10, PC11, PC13, PC14 and PC22), as mentioned previously. In this case, the Miners' law $[33,34]$ was used in order to homogenize the number of cycles under different load levels. However, it was seen that the effect of the number of cycles corresponding to the lowest load level was negligible. Thus, although plotted in Fig. 6, these data were not considered in the analysis.

Due to the fact that the crack length could be observed from both sides of the specimen, some discontinuities can appear (as in Fig. $6 \mathrm{c}$ for PC10) when reproducing the data obtained from the two sides for different load levels (PC10 under $8409 \mathrm{~N}$ does not start with a crack length corresponding to that obtained at $6540 \mathrm{~N}$ load level).

Generally speaking, the progression of the crack for every group of specimens presented only small scatter, although some exceptions appeared. For instance, the pictures of PC23 were taken on different days, which can justify the high value of Dz (up to 60000 cycles) that can be observed in Fig. 6 g.

The angle of failure initiation is indicated in the schematic of the corner for each case in Fig. 6, showing the direction of propagation at the initiation stage and the applied load. Thus, when the first failure was observed at $0^{\circ}$ it meant that the failure was firstly at the CFRP-adhesive interface, along the $\mathrm{x}$-axis (parallel to the fibres, according to the coordinate system of Fig. 1 d). By analogy, the angle of $90^{\circ}$ for initiation meant that the failure went along the CFRP-adhesive interface, but along the $y$-axis (perpendicular to the fibres). Although the crack generally started at angles of $0^{\circ}$ or $90^{\circ}$, when it propagated through the adhesive, the rupture tended to adopt a straight vertical line, i.e. the same direction as the applied load and perpendicular to the indirect tensile stress that is typically developed in the original BT [19]. However, when the CFRP was involved in the failure mechanism (cases in which $\alpha=13^{\circ}$ or $30^{\circ}$, in which the load line passed through the CFRP), the 
interface failure prevailed, followed by the failure in the adhesive. In all specimens with $\alpha=13^{\circ}$, $30^{\circ}, 143^{\circ}$ and $150^{\circ}$, the failure started at the interface parallel to the fibres (taking the coordinate system of Fig. 1.d as reference), with the exception of PC20 $\left(\alpha=143^{\circ}\right)$ where is not fully clear that the failure started at that interface. For $\alpha=90^{\circ}, 115^{\circ}, 120^{\circ}$ the failure started at the interface perpendicular to the fibres. It is clear that the direction of the applied load governs the behaviour, the closest interface to the line in which the load was applied being the one failing first. A proof of this can be obtained by comparing the failure paths for $\alpha=120^{\circ}$ and $\alpha=150^{\circ}$ configurations. In both cases, the closest interfaces are $30^{\circ}$ from the line of load application, but closest to the fibres in $0^{\circ}$ for $\alpha=120^{\circ}$ (Fig. 6 e) and to the fibres in $90^{\circ}$ for $\alpha=150^{\circ}$ (Fig. 6 g). The observed initial failure path direction suggests that the initiation of the damage or visible crack started independently of the fibres orientation, due to the lack of symmetry and to the different stiffness and strength properties of the CFRP and the interface (in general for $\alpha=120^{\circ}$ the specimens reached $\mathrm{Dz} \geq 10 \mathrm{~mm}$ faster than for $\alpha=150^{\circ}$ ).

Figure 7 shows the averaged (over the three specimens in each configuration) number of cycles $\mathrm{N}_{0}$, $\mathrm{N}_{1 \mathrm{~mm}}, \mathrm{~N}_{3 \mathrm{~mm}}$ (represented on the left side of the axis) for each angle tested $(\alpha) . \mathrm{P}_{\max }$ (applied in all specimens) was normalised with $\mathrm{P}_{\mathrm{u}}$ (extrapolated from static tests [18] to the dimensions of the actual specimens), and represented as $\% \mathrm{P}_{\mathrm{u}}$ on the right side axis. For the configuration $\alpha=60^{\circ}$, where failure did not occur, the infinite life was indicated with an arrow. It can be appreciated from Fig. 7 how similar the trend of fatigue damage (initiation in $\mathrm{N}_{0}$ curve, 1 $\mathrm{mm}$ in $\mathrm{N}_{1 \mathrm{~mm}}$ curve and $3 \mathrm{~mm}$ in $\mathrm{N}_{3 \mathrm{~mm}}$ curve) with loading angle is, particularly for the range between $\alpha=120^{\circ}$ and $\alpha=150^{\circ}$. With $\alpha=90^{\circ}$ and $\alpha=13^{\circ}$ the failure started and almost instantaneously reached a length of $3 \mathrm{~mm}$. An important observation from Fig. 7 was the evidence that the brittle fracture was not due to the value of the extreme $\mathrm{P}_{\max }$ load during the tests. For example when $\alpha=60^{\circ}$ the $\mathrm{P}_{\max }$ applied during the test corresponded to approximately $58 \%$ of $\mathrm{P}_{\mathrm{u}}$ and no fatigue damage was noted. However, the percentage was slightly lower for $\alpha=120^{\circ}(54 \%$ of $\mathrm{P}_{\mathrm{u}}$ ), and for this configuration the failure started earlier (namely $\mathrm{N}_{0}=2500$ cycles 
approximately, see also Table 1), although it grew slower (the number of cycles needed to reach 1 $\mathrm{mm}$ is relatively high, namely, $\mathrm{N}_{1 \mathrm{~mm}}=22500$ cycles on average). Also, it is observable from Fig. 7, that when $K_{1}$ tends to zero (see also Fig. 2), fatigue life increases significantly. This might imply that fatigue is driven by $\mathrm{K}_{1}$. Conversely, no significant influence on fatigue failure is observed when $K_{2}$ tends to zero, implying that $K_{2}$ may not play as important role in fatigue as $K_{1}$. Finally and for the sake of clarity, the normalized values (in order to obtain $\mathrm{K}_{1}=1$ on $\mathrm{x}$-axis and $\mathrm{K}_{2}=1$ on $\mathrm{y}$-axis in the dimensionless failure envelope as in [18]) of $\mathrm{K}_{1}{ }^{*}$ and $\mathrm{K}_{2}{ }^{*}$ are depicted in Fig. 8, which shows $\mathrm{N}_{0} / \mathrm{N}_{1 \mathrm{~mm}}$ and $\mathrm{N}_{0} / \mathrm{N}_{3 \mathrm{~mm}}$ ratios versus the angle $(\alpha)$. The GSIFs (indicated in parentheses) are related with the results from fatigue tests, giving the limits for initiation (ratio $\mathrm{N}_{0} / \mathrm{N}_{1 \mathrm{~mm}}$ ) and final failure (ratio $\mathrm{N}_{0} / \mathrm{N}_{3 \mathrm{~mm}}$ ). The case of $\alpha=60^{\circ}$ is not included in Fig. 8. The physical meaning for the behaviour shown in this plot can be found when the ratio $\mathrm{N}_{0} / \mathrm{N}_{1 \mathrm{~mm}}$ was close to 1 , meaning that the crack quickly reached the length of $1 \mathrm{~mm}$. It was also observed that the ratios followed a similar trend with the angle. The progression of the observable damage was then represented in the plots as the area included between these ratios (i.e., the area represents the region in which the whitening/visible crack is being developed). Comparing Fig. 8 with Fig. 2, it is observed that the fatigue damage increased when $\mathrm{K}_{1}{ }^{*}$ increased. Nevertheless, it is important to notice that the GSIFs were not updated with the progression of damage, only values corresponding to intact Brazilian disk specimens having been used.

\subsection{Crosshead data}

The information on the crosshead displacement of the machine (specimen compliance) during the test was analyzed in order to check if the compliance change could be correlated with the crack onset, thus providing a way of anticipating fatigue damage. Figure 9 shows the maximum and minimum displacement (i.e. Max and min as red and blue curves), and the difference between them (i.e., Max-min as green curve). The displacement range is shown on the left vertical axis during the test for specimen PC16 $\left(\alpha=120^{\circ}\right)$ and the Max and min values were represented in Fig. 9 , by subtracting them from the mean value, i.e. $(\operatorname{Max}+\min ) / 2$ of the first cycle. 
From the visual data in Fig. 6, it is known that the crack had exceeded $3 \mathrm{~mm}$ by 37500 cycles for specimen PC16 (Fig. 9), so this would imply that compliance change is not a very satisfactory way to detect local fatigue damage up to $3 \mathrm{~mm}$. Consequently, the crosshead data can be considered as a poor indicator for failure initiation and progression.

\section{Summary conclusions}

Brazilian disk specimens having a bimaterial closed corner at the centre of the disk were tested under fatigue load at different diametral compression angles. Under static load condition these specimens were successfully used for failure prediction in adhesive DLJ [17, 18]. The tests allowed complete mapping of the initiation and progression of the damage or crack in such bimaterial corner configuration.

In previous analyses [18] under static load as the failure observed was sometimes very sudden, with a brittle behaviour, it was not possible to verify experimentally that the failure really started at the corner tip. Thus, one of the main conclusions/contributions of this work is that it has been verified experimentally that the failure started at the corner tip, for all specimens where failure was observed, corroborating and validating previous analyses and other theoretical studies.

All specimens tested with the same angle presented similar failure mechanisms, although different angles gave rise to distinct failure mechanisms. The data from the fatigue testing were classified according to the number of cycles to reach the final failure (associated with a $3 \mathrm{~mm}$ crack length). It was observed that for all cases the failure initiation occurred along one of the CFRP-adhesive interfaces (the interface most aligned to the load was prone to initiate the failure). The failure path direction was not influenced by the lack of symmetry, since it was observed that the failure always started at one of the CFRP-adhesive interfaces.

The development of the failure observed in the experiments can be summarized in three main stages: 1) Initiation at the corner tip, where whitening, damage or a visual crack arose; 2) Propagation, along the interface that could go simultaneously or independently through the adhesive, depending on the load angle; 3 ) Final failure of the component ( $3 \mathrm{~mm}$ crack length). 
The group of specimens with $\alpha=60^{\circ}$ did not show any visible failure. This fact, together with the retarded failure observed in the specimen with $\alpha=143^{\circ}$ (angles $60^{\circ}$ and $143^{\circ}$, where $\mathrm{K}_{1} \cong 0$ ), suggests that $\mathrm{K}_{1}$ drives the fatigue failure. Thus, fatigue life diminishes drastically when approaching angles with significant $\mathrm{K}_{1}$ values associated, Figs. 2 and 7.

The study carried out corresponds to a critical point for the prediction of failure in the most commonly bimaterial corner found in structural adhesive joints. This study can be easily extended to other corner configurations also present in adhesive joints.

\section{Acknowledgments}

This work was supported by CAPES Brazilian Ministry of Education, EADS chair in Seville, also by the Junta de Andalucía and European Social Fund through the Projects of Excellence P08-TEP4071 and P08-TEP-4051. The authors would like to give thanks to Peter Haynes for the help in setting up the testing.

\section{References}

[1] O. Volkersen. Luftfahrtforschung 15, 41 (1938).

[2] N. A. de Bruyne. Aircraft Eng. Aerospace Technol. 16, 115 (1944).

[3] M. Goland and E. Reissner. ASME Trans., J. Appl. Mech. 11, A17 (1944).

[4] T. Wah. ASME Trans., J. Eng. Mater. Technol. 95, 174 (1973).

[5] L. J. Hart-Smith. NASA CR-112235 (1973).

[6] L. J. Hart-Smith. NASA CR-2218 (1974).

[7] M.Y. Tsai, J. Morton and D. W. Oplinger. Expl. Mech. 36, 297 (1996).

[8] M.Y. Tsai, D. W. Oplinger and J. Morton. lnt. J. Solids Struct. 35, 1163 (1998).

[9] D.A. Bigwood and A.D. Crocombe. Int. J. Adhesion Adhesives 9, 229 (1989).

[10] D.A. Bigwood and A.D. Crocombe. Int. J. Adhesion Adhesives 10, 31 (1990).

[11] L. F. M. da Silva, P. J. C. Neves, R. D. Adams and J. K. Spelt. Int. J. Adhesion Adhesives 29, 319 (2009).

[12] L. F. M. da Silva, P. J. C. Neves, R. D. Adams, A. Wang and J. K. Spelt. Int. J. Adhesion Adhesives 29, 331 (2009).

[13] T. Hattori. J. Jpn. Soc. Mech. Eng. 34, 326 (1991). 
[14] L. Banks-Sills and D. Ashkenazi. Int. J. Fract. 103, 177 (2000).

[15] M. L. Dunn, C. Y. Hui, P. E. W. Labossiere and Y. Y. Lin. Int. J. Fract. 110, 101 (2001).

[16] D. Leguillon and E. Sanchez-Palencia, Computation of Singular Solutions in Elliptic

Problems and Elasticity. Masson Ed., Paris (1987).

[17] A. Barroso, D. Vicentini, V. Mantič and F. París. Determination of generalized fracture toughness in composite multimaterial closed corners with two singular terms.

Part I: test proposal and numerical analysis (submitted for publication in Eng. Fract. Mech., 2011).

[18] D. Vicentini, A. Barroso, J. Justo, V. Mantič and F. París. Determination of generalized fracture toughness in composite multimaterial closed corners with two singular terms.

Part II: experimental results (submitted for publication in Eng. Fract. Mech., 2011).

[19] F. Carneiro and A. Barcellos. RILEM Bull. 13, 97 (1953).

[20] A. Barroso, F. París and V. Mantič. Composites Sci. Technol. 69, 1746 (2009).

[21] I.A. Ashcroft, D.J. Hughes, S.J. Shaw, M. Abdel Wahab and A. Crocombe. J. Adhesion 75, 61 (2001).

[22] A. Barroso, D. Vicentini, F. París and V. Mantič. Composites Part A 42, 1084 (2011).

[23] A. Barroso, E. Graciani, V. Mantič and F. París. Eng. Anal. Boundary Elem. 36, 458 (2012).

[24] A. Barroso, V. Mantič and F. París. Int. J. Fract. 119, 1 (2003).

[25] J.S. Wang and Z. Suo. Acta Metall. Mater. 38, 1279 (1990).

[26] M. L. Williams. ASME Trans., J. Appl. Mech. 19, 526 (1952).

[27] S. P. Pageau, K. S. Gadi, Jr. S. B. Biggers and P. F. Joseph. Int. J. Fract. 77, 51 (1996).

[28] M. T. Akazawa. RILEM Bull. 16, 12 (1953).

[29] G. Tesoriere and S. Marino, in: Proceedings of the $4^{\text {th }}$ Int. Symp. held by RILEM, Budapest, 320-328 (1990).

[30] A. Carpinteri and M. Paggi. Mater. Sci. 42, 95 (2006).

[31] D. Vicentini, A. Barroso, V. Mantič, F. París and D. Canales, in: Proceedings of IX

MATCOMP, Girona, Spain, 861 (2011).

[32] M. K. Fahad. J. Mater. Sci. 31, 3723 (1996).

[33] M. A. Miner. ASME Trans., J. Appl. Mech. 67, A 159 (1945).

[34] I. A. Ashcroft, V. Shenoy, G. W. Critchlow and A. D. Crocombe. J. Adhesion 86, 1203 (2010). 
Table 1. Summary list of data from numerical and experimental analyses. $\mathrm{K}_{1}{ }^{*}$ and $\mathrm{K}_{2}{ }^{*}$ were obtained from the estimation of $P_{u}$ ([18] results), being presented as averaged and normalized values.

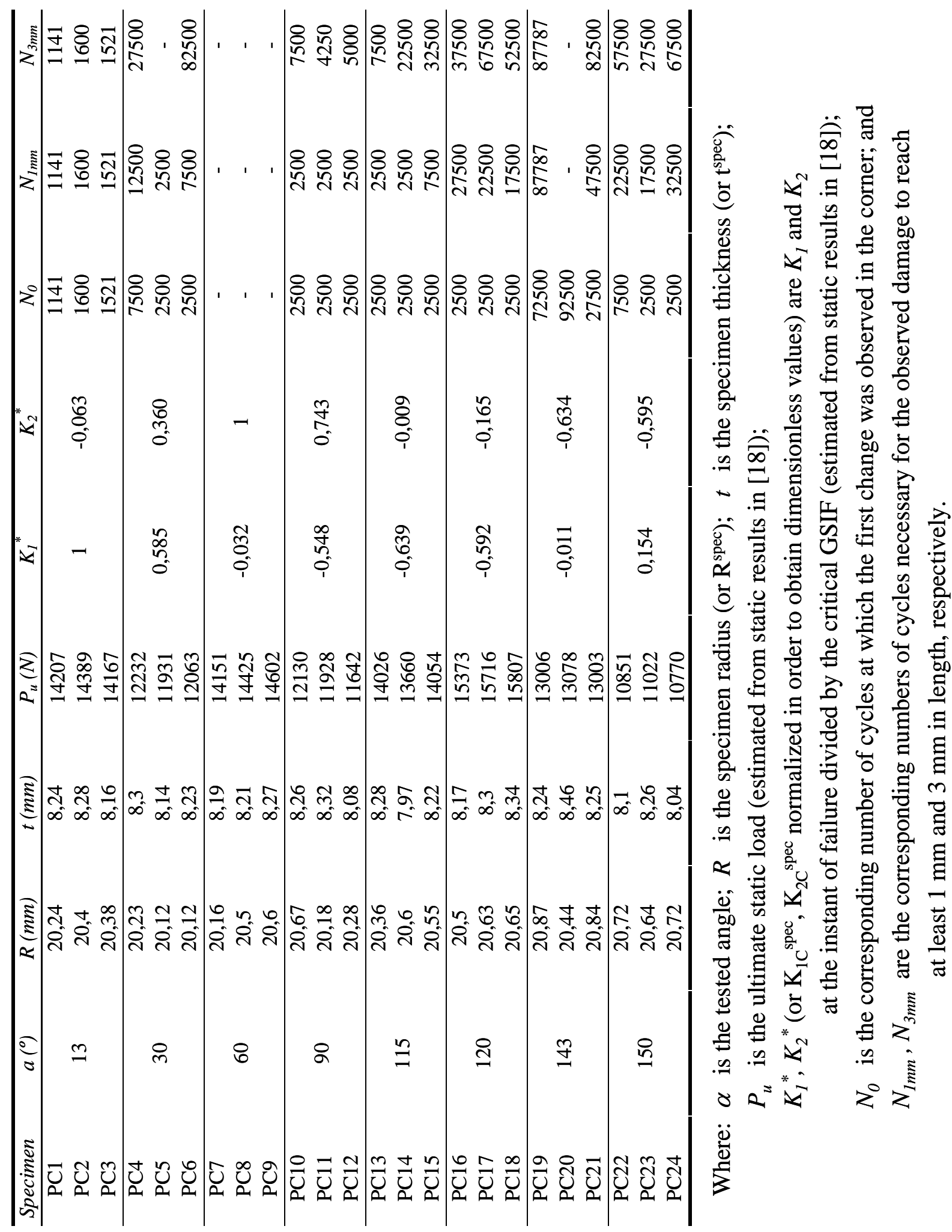


c) Corner in $D L J$
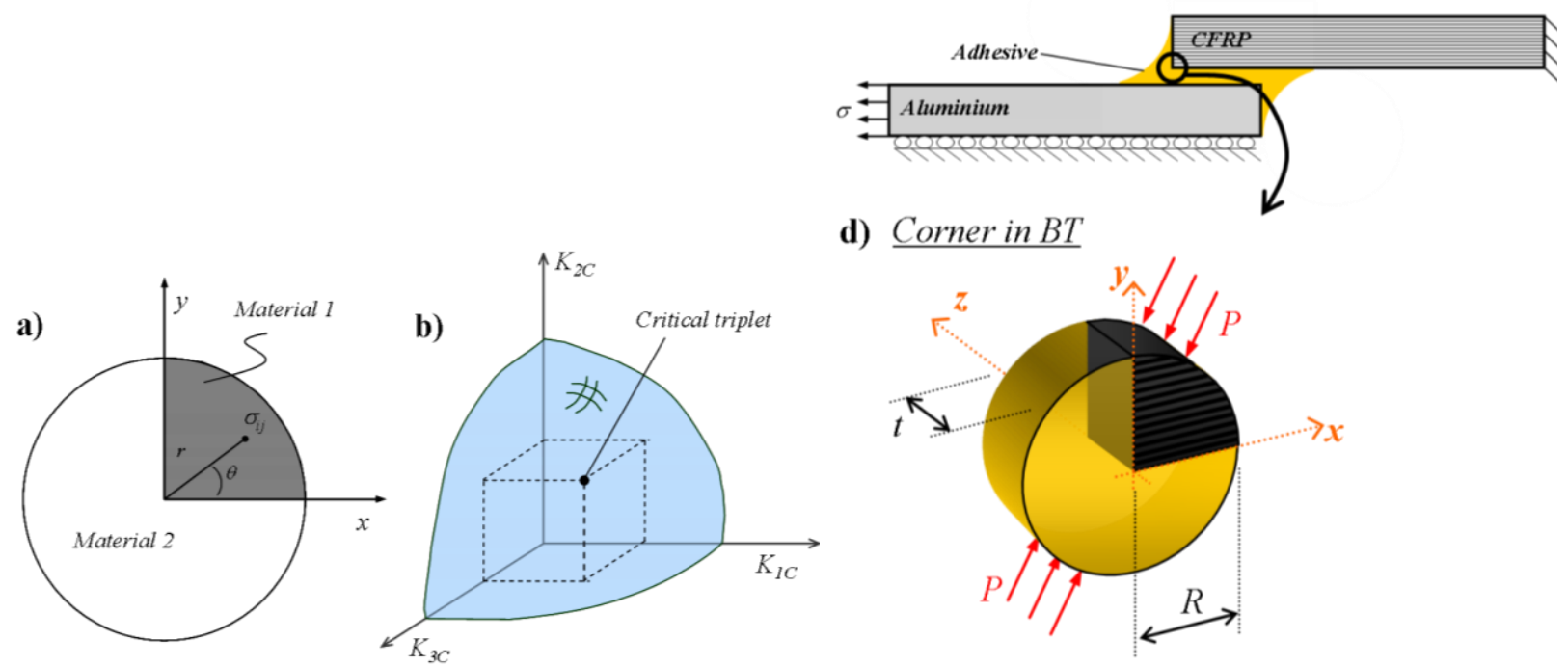

d) Corner in BT

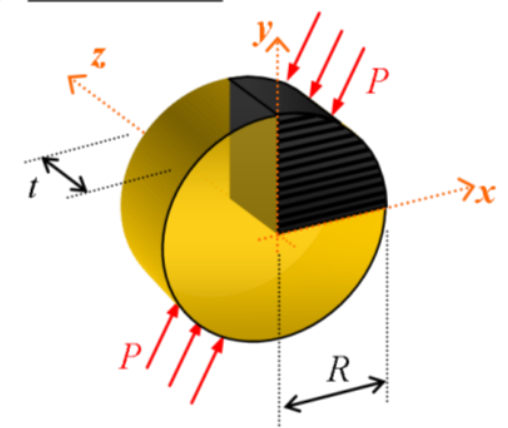

Fig. 1. (a) Bimaterial corner, (b) scheme of a failure envelope based on critical values of GSIF considering 3 terms, (c) DLJ indicating a detail of the amplified corner with diametral forces being applied (d), as in Brazilian Test specimens.

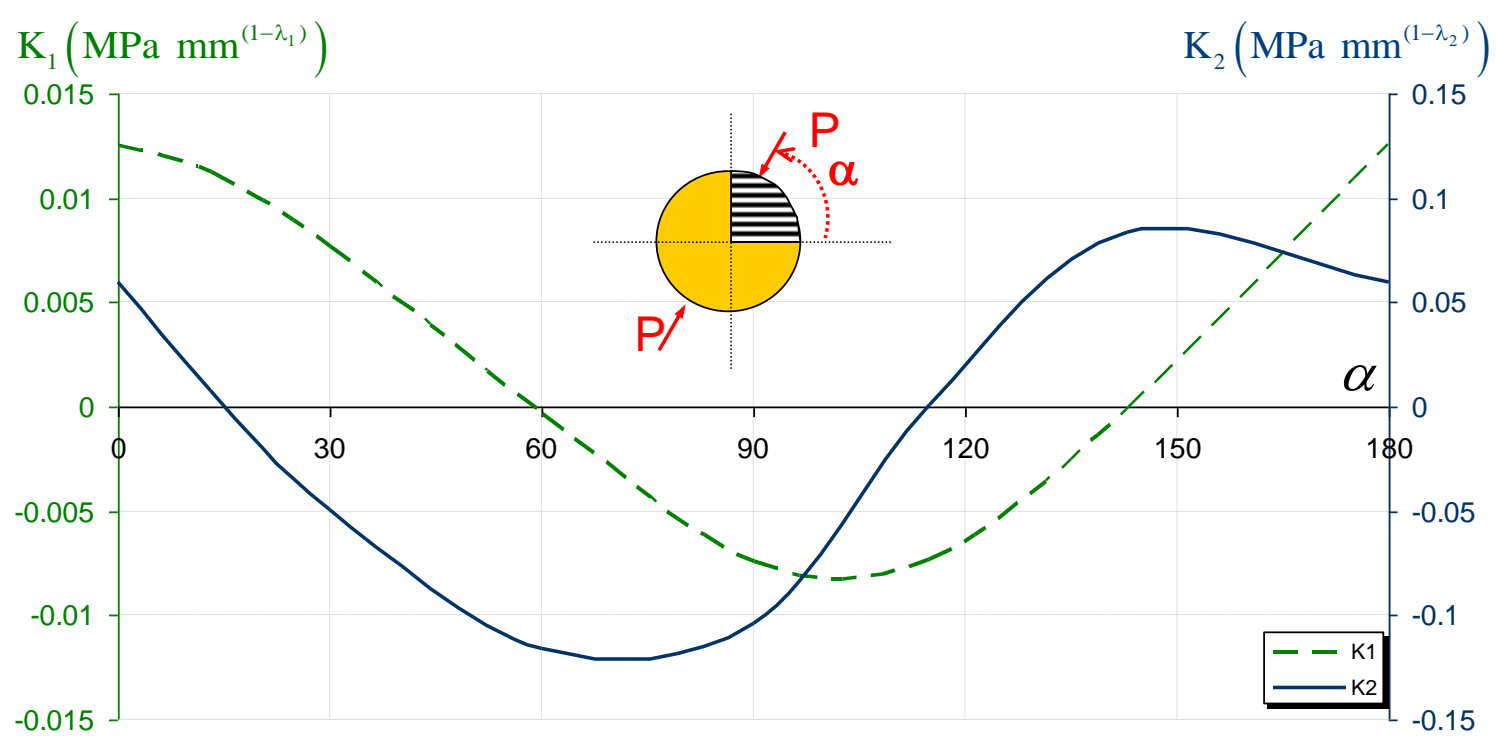

Fig. 2. Distribution of $K_{1}$ and $K_{2}$ for different angles $\alpha$ (in degrees). 

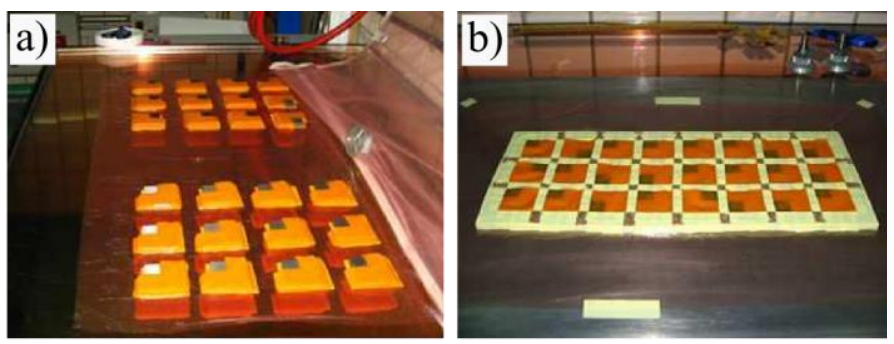

c)

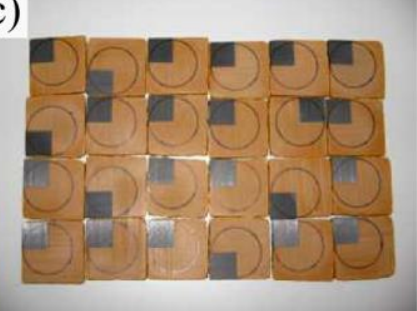

d)

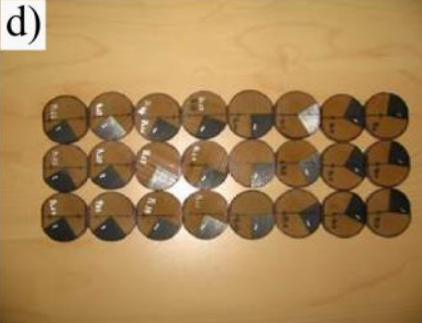

Fig. 3. Fabrication of specimens. a) Adhesive film being layered; b) Cork covered with high temperature tape demarcating the region; c) After curing, specimens are like "cookies" and d)

Final geometry of samples.
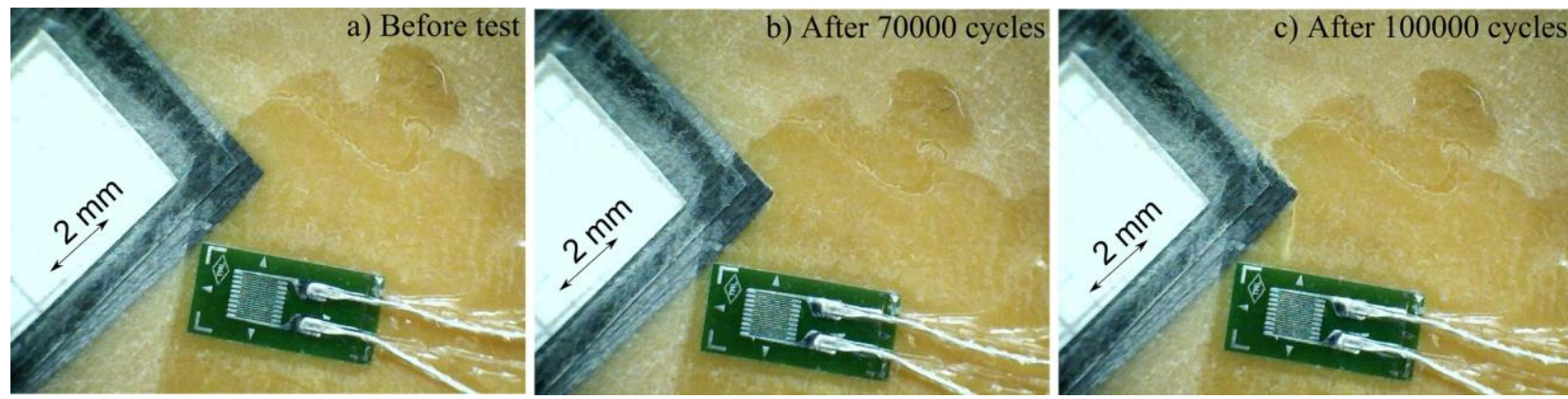

Fig. 4. Examples of sequential frames of pictures of PC21, case $\alpha=143^{\circ}$. The strain gauge is seen in these pictures.
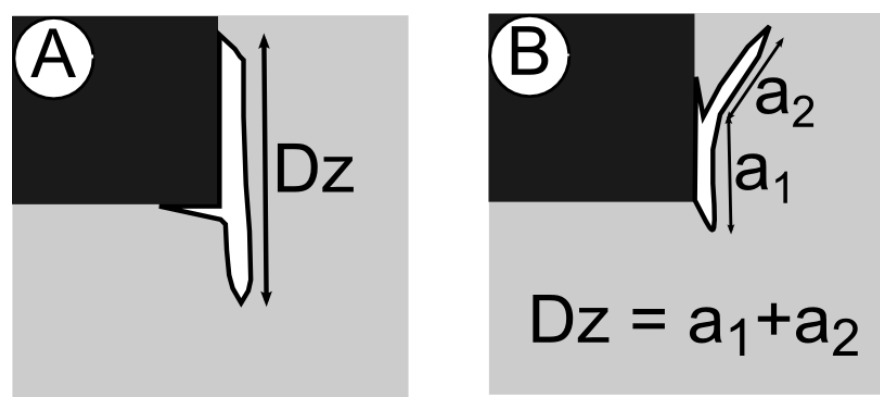

Fig. 5. Measurement of the size for irregular failure paths a) type I and b) type II, where Dz is the damage zone (or crack) length. 


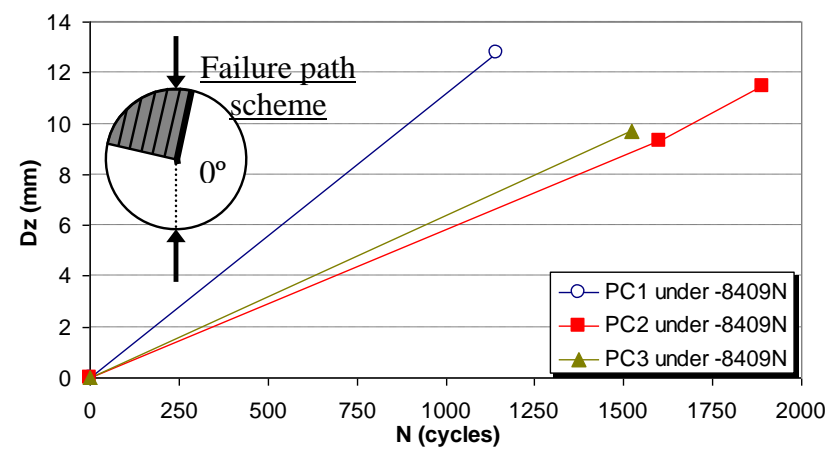

a) $\alpha=13^{\circ}$

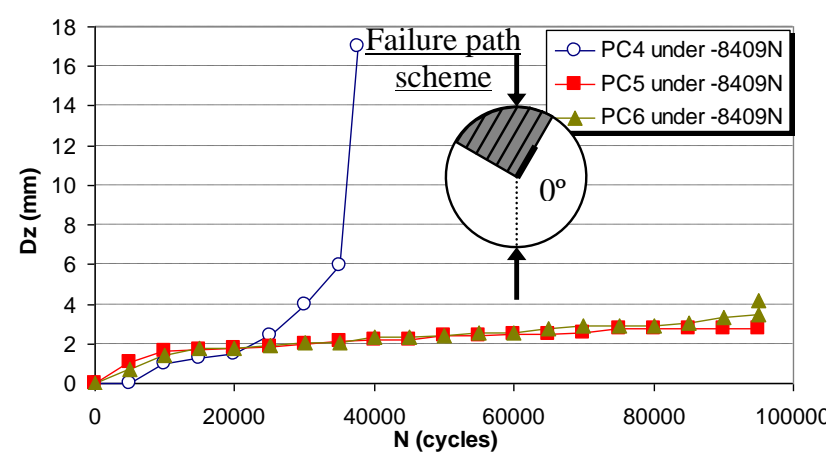

b) $\alpha=30^{\circ}$

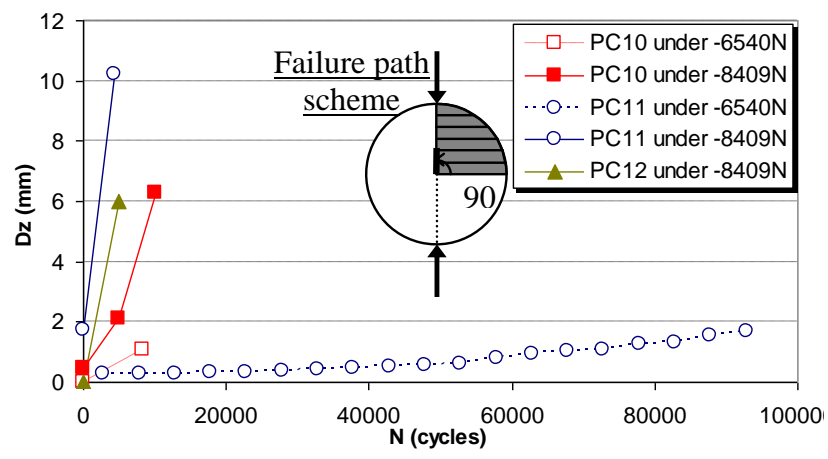

c) $\alpha=90^{\circ}$

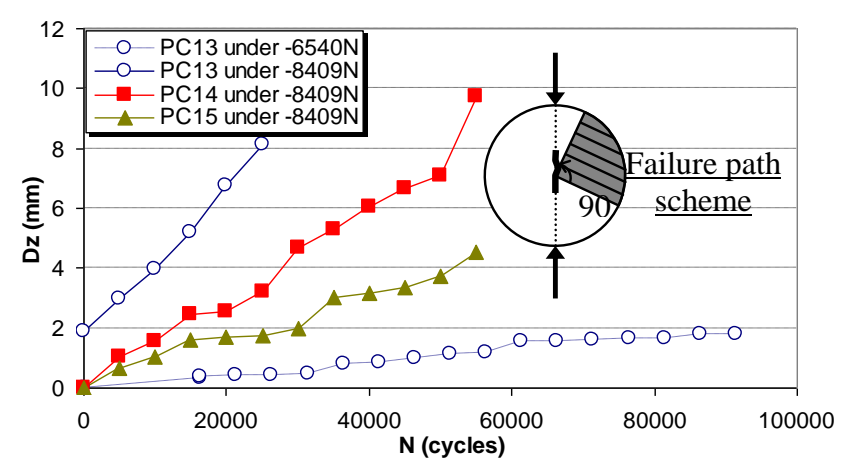

d) $\alpha=115^{\circ}$

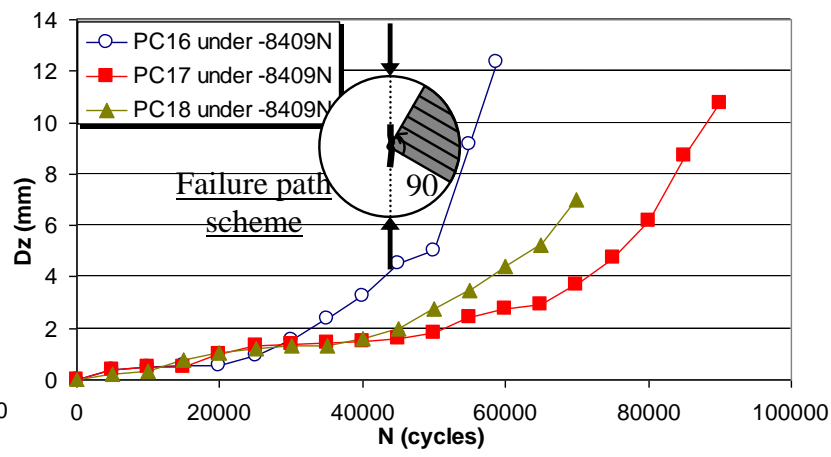

e) $\alpha=120^{\circ}$

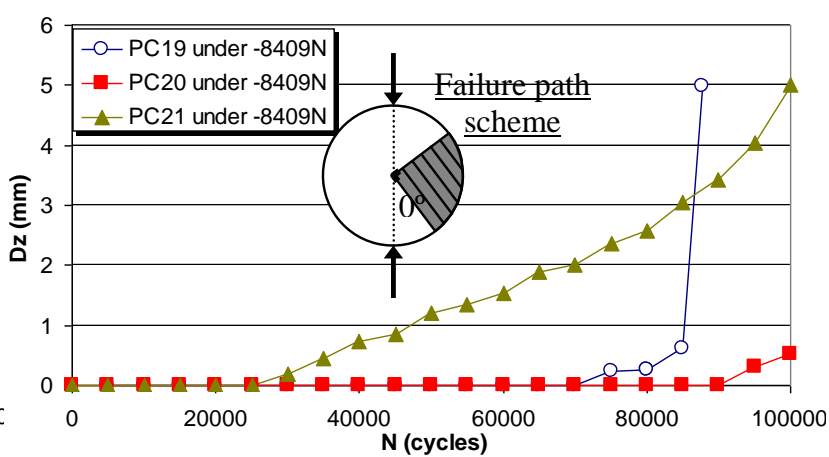

f) $\alpha=143^{\circ}$

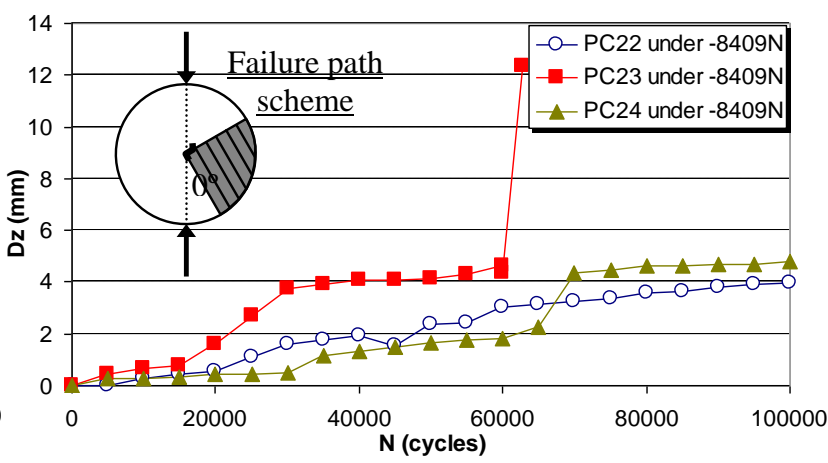

g) $\alpha=150^{\circ}$

Fig. 6. Damaged zone $(D z)$ vs. number of cycles $(N)$ for every tested angle $(\alpha)$. A scheme of the failure path observed during the test is also indicated in each case. 


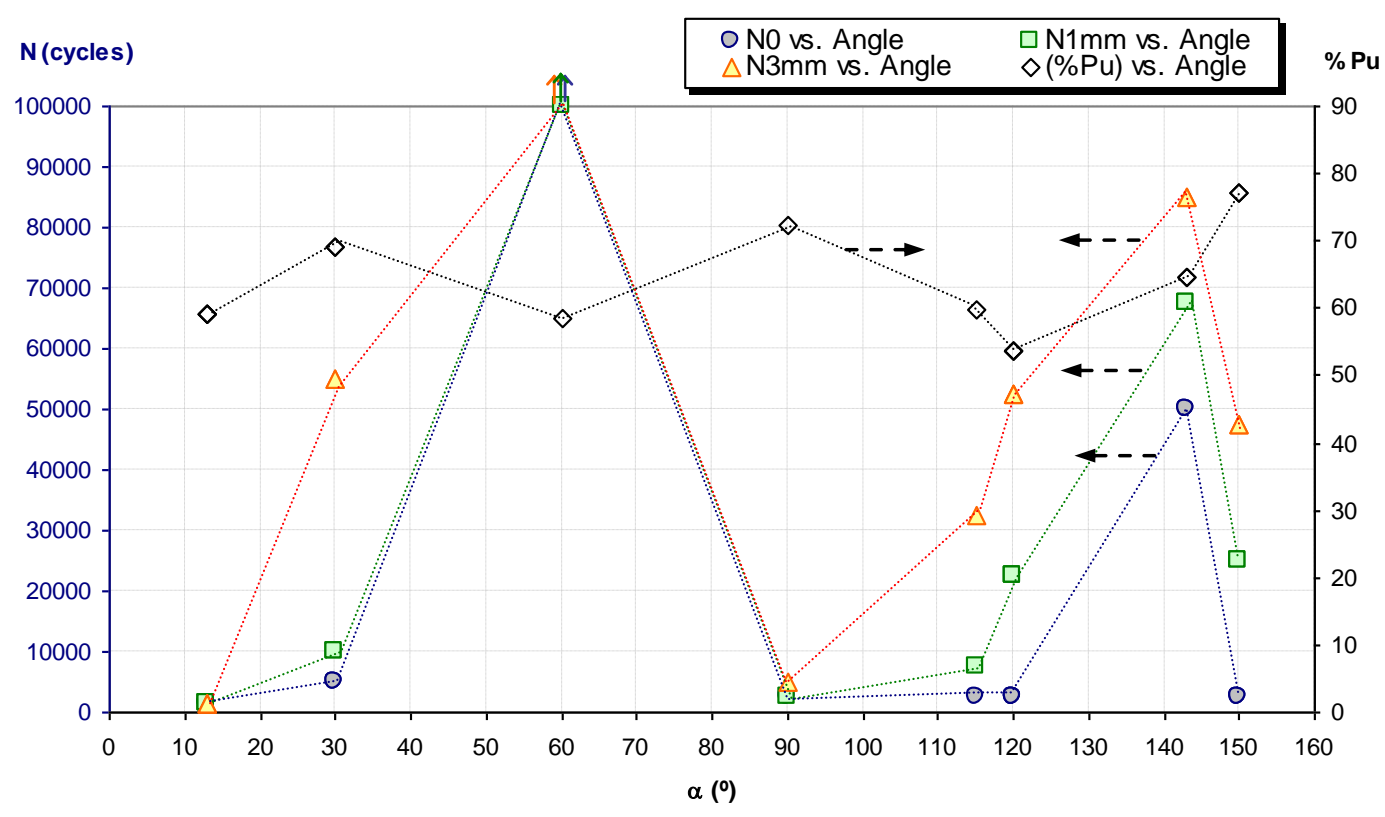

Fig. 7. Averaged number of cycles $\left(\mathrm{N}_{0}, \mathrm{~N}_{1 \mathrm{~mm}}\right.$ and $\mathrm{N}_{3 \mathrm{~mm}}$, left axis) and \% of ultimate load (right axis) versus load orientation $(\alpha)$.

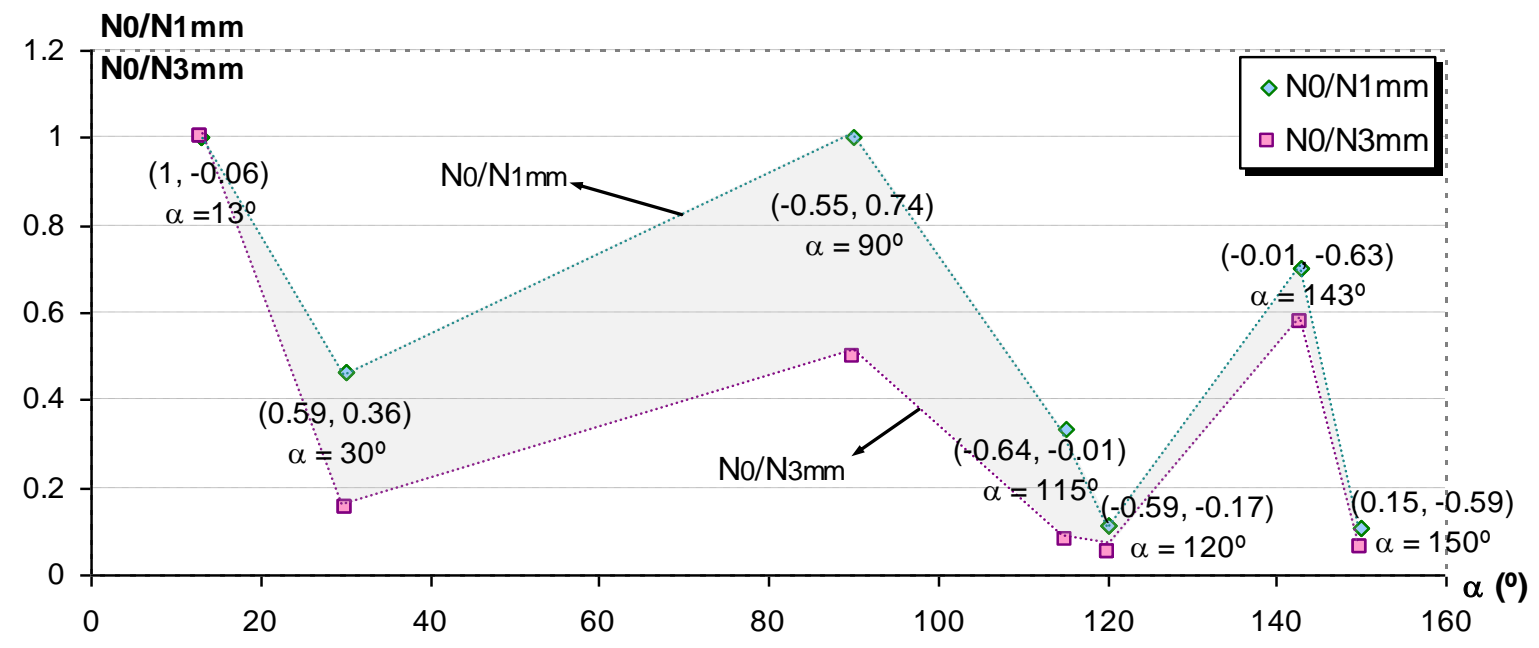

Fig. 8. $N_{0} / N_{1 m m}$ and $N_{0} / N_{3 m m}$ versus angle $\alpha$, with $\left(\mathrm{K}_{1}{ }^{*}, \mathrm{~K}_{2}{ }^{*}\right)$ indicated.

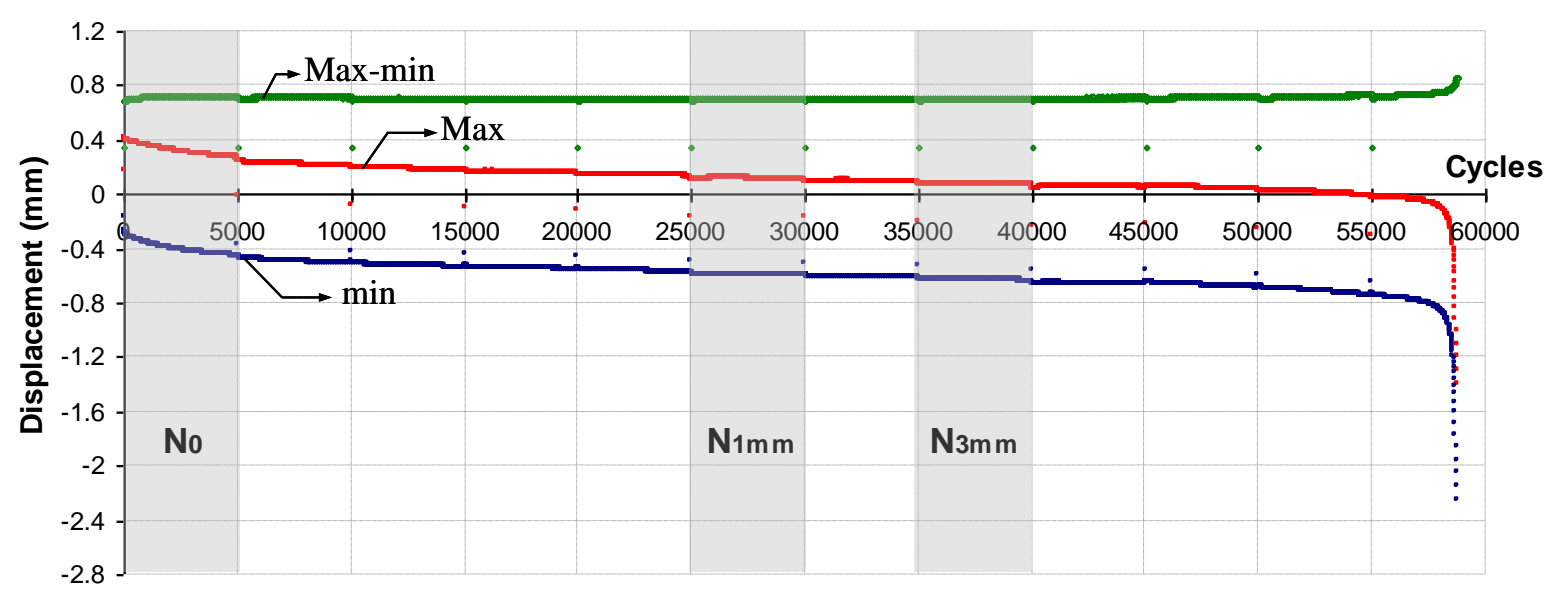

Fig. 9. Crosshead displacement during the test for $\operatorname{PC} 16\left(\alpha=120^{\circ}\right)$. 